\title{
Thermal stability, flammability and fire hazard of butadiene-acrylonitrile rubber nanocomposites
}

\author{
Grażyna Janowska • Agnieszka Kucharska-Jastrząbek • \\ Przemysław Rybiński
}

Received: 6 August 2010/Accepted: 22 December 2010/Published online: 13 January 2011

(C) The Author(s) 2011. This article is published with open access at Springerlink.com

\begin{abstract}
This article presents the effect of the method of NBR cross linking on the thermal properties, flammability and fire hazard of its nanocomposites containing modified montmorillonite (NanoBent or Nanofil), using test results obtained by means of a derivatograph, oxygen index and cone calorimetry. It has been found that the thermal stability and flammability of the nanocomposites investigated depend on both the rubber network structure and the type of montmorillonite. The nanoadditives used reduce the flammability of cross-linked nitrile rubber and considerably limit its fire hazard.
\end{abstract}

Keywords Nitrile rubber - Thermal analysis . Thermal stability · Flammability · Fire hazard . Nanofillers · Montmorillonite

\section{Introduction}

Recent years have witnessed a great interest in polymeric materials of special properties such as resistance to considerably lowered or elevated temperature, flame-retardation and appropriate mechanical strength. The most important of them seems the issue of reduced flammability of polymeric products, which results, first of all, from

G. Janowska · A. Kucharska-Jastrząbek

Technical University of Łódź, Institute of Polymer and Dye

Technology, Łódź, Poland

P. Rybiński ( $₫)$

Department of Management and Protection Environment,

Jan Kochanowski University of Humanities and Sciences,

Kielce, Poland

e-mail: przemek100@ujk.kielce.pl health and life protection and also from economical reasons. Thus, the processes by which polymers are affected at elevated temperatures, phenomena that accompany their combustion such as emission of heat, toxic substances and smoke as well as flame propagation and glowing $[1,2]$ are considered to be very significant.

Considerable opportunities to obtain flame-retardant polymeric materials result from the development of nanotechnology. A growing interest is focused on inorganic nanofillers, i.e. nanosilica, and natural layered silicates such as kaolinite, halloysite, illite, endelite, smectite and the most commercially important montmorillonite belonging to the group of 2:1 phylosilicates [3, 4].

The resistance of polymeric nanocomposites to the action of flame can be improved by the intercalation of organically modified layered silicates (OLSs) in the polymer matrix. A small addition of this kind of filler, about 3-5 parts by wt. per 100 parts by wt. of rubber appropriately dispersed in the polymeric matrix, creates a considerably larger surface of polymer-filler interaction than that of conventional fillers. As a result, the oscillation amplitude of polymeric chain segments is reduced and consequently the temperatures of degradation and destruction of the filled polymer are increased [4].

The increase in the thermal stability of nanocomposites is connected also with the formation of a boundary carbon layer whose insulating properties considerably limit the flow of mass and energy between sample and flame. It inhibits the thermal decomposition of polymer, radical combustion processes and the emission of toxic products of thermal decomposition and combustion of the filled composite. This is extremely important from the point of view of environmental protection.

This article presents the investigation results of the effect of montmorillonite modified by means of various 
organic compounds on the thermal stability and flammability of cross-linked nitrile rubber.

\section{Experimental}

Materials

We investigated nanocomposites of butadiene-acrylonitrile rubber (NBR), Perbunan 2255V from Lanxess Deutschland GMBH, containing $22 \%$ of combined acrylonitrile. The rubber was cross linked with the use of:

(a) dicumyl peroxide, DCP, (0, 3 parts by wt.) in the presence of zinc oxide, $\mathrm{ZnO}$, (5 parts by wt.) and stearic acid (1 part by wt.)-peroxide vulcanizate denoted with $N$.

(b) elementary sulphur (1, 5 parts by wt.) with a vulcanization accelerator: $N$-cyclohexyl-2-benzoylsulfenamide, Tioheksam CBS (2 parts by wt.) in the presence of zinc oxide, $\mathrm{ZnO}$, (5 parts by wt.) as vulcanization activator and stearic acid (1 part by wt.)—sulphur vulcanizate denoted with $S$.
The following nanobentonites were used as fillers of elastomer blends: NanoBent ZS-1 (ZS), NanoBent ZR-2 (ZR), NanoBent ZW-1 (ZW) from ZGM "Zębiec" and Nanofil 2 (N2), Nanofil 5 (N5), Nanofil 15 (N15) from SüdChemie. Their characteristics are given in Table 1.

Methods

The nanobentonites were incorporated into the elastomer blend in a quantity of 3,5 or 8 parts by wt. per 100 parts by wt. of rubber. The elastomer blends were prepared at room temperature with the use of a laboratory rolling mill with roll dimensions: $D=150 \mathrm{~mm}, L=300 \mathrm{~mm}$. The rotational speed of the front roll was $20 \mathrm{rpm}$, and the friction ratio was 1.1 .

The blends were vulcanized in steal moulds placed between electrically heated press shelves. The optimal vulcanization time $\left(\tau_{0.9}\right)$ at a temperature of $160{ }^{\circ} \mathrm{C}$ was determined by means of a WG-2 vulcameter according to standard PN-ISO 3417:1994.

The thermal properties of nanobentonites and nanobentonite-containing vulcanizates were tested under air atmosphere within the temperature range of $25-800{ }^{\circ} \mathrm{C}$, by

Table 1 Characteristics of aluminosilicates (producer's data)

\begin{tabular}{|c|c|c|c|c|}
\hline Trade mark (symbol) & Producer & Modifying agent & $\begin{array}{l}\text { Average size } \\
\text { of grains } / \mu \mathrm{m}\end{array}$ & $\begin{array}{l}\text { Interlayer } \\
\text { spacing/nm }\end{array}$ \\
\hline NanoBent ZS-1 (ZS) & $\begin{array}{l}\text { ZGM "Zębiec" and Technical } \\
\text { University of Szczecin }\end{array}$ & $\begin{array}{l}4^{\circ} \text { ammonium salt containing } \mathrm{OH} \\
\text { groups }\end{array}$ & $20-60(81 \%) \leq 20(19 \%)$ & $3.8-3.9$ \\
\hline NanoBent ZR-2 (ZR) & $\begin{array}{l}\text { ZGM "Zębiec" and Technical } \\
\text { University of Szczecin }\end{array}$ & $\begin{array}{l}4^{\circ} \text { ammonium salt with two short } \\
\text { and two long carbon-chain } \\
\text { substituents }\end{array}$ & $20-60(56 \%) \leq 20(44 \%)$ & $2.0-2.4$ \\
\hline NanoBent ZW-1 (ZW) & $\begin{array}{l}\text { ZGM "Zębiec" and Technical } \\
\text { University of Szczecin }\end{array}$ & $\begin{array}{l}4^{\circ} \text { ammonium salts derivative of } \\
\text { 3-dimetyloaminopropylo-amide } \\
\text { of fatty acid }\end{array}$ & $20-60(54 \%) \leq 20(46 \%)$ & $1.8-1.9$ \\
\hline Nanofil 2 (N2) & Süd-Chemie & Ampholytic compound SBMAC & 8 & 1.8 \\
\hline Nanofil 5 (N5) & Süd-Chemie & Ampholytic compound SMAC & 8 & 2.8 \\
\hline Nanofil 15 (N15) & Süd-Chemie & & 25 & 2.8 \\
\hline
\end{tabular}

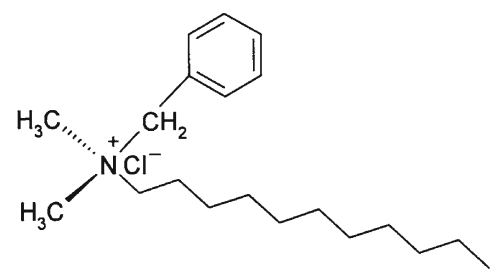

SBMAC

stearilobenzylodimetyloammonium chloride

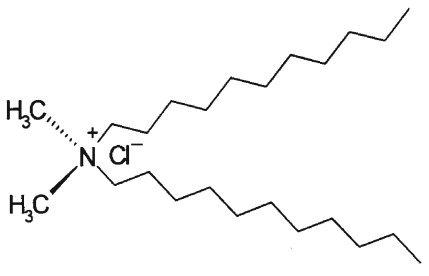

SMAC

distearilodimetyloammonium chloride 
means of a Paulik, Paulik, Erdey derivatograph, using $\mathrm{Al}_{2} \mathrm{O}_{3}$ as a reference substance. The weight of a sample was $90 \mathrm{mg}$, heating rate was $7.9^{\circ} \mathrm{C} / \mathrm{min}$, and then the sensitivities of thermal curves were as follows: $\mathrm{TG}=100$, $\mathrm{DTA}=1 / 5, \mathrm{DTG}=1 / 30$.

The flammability of nanocomposites was determined by the method of oxygen index (OI) using an apparatus of our own construction [5] and shaped samples with dimensions $50 \times 10 \times 4 \mathrm{~mm}$. With a constant nitrogen flow rate of $400 \mathrm{~L} / \mathrm{h}$, the oxygen flow was selected so that the sample tested was totally burned, including flame decay, within $t=180 \mathrm{~s}$. The sample top was ignited for $15 \mathrm{~s}$ by means of a gas burner using a propane-butane mixture $[1,6]$. The value of OI was expressed in the form of a quotient of oxygen concentration to the concentration of oxygennitrogen mixture flowing through the measuring column.

Flammability tests were also carried out in air using the same samples as in the case of OI tests. A vertically situated sample was ignited as previously for $15 \mathrm{~s}$ followed by measuring the time of its combustion or the time after which the sample was extinguished; the length of unburned sample was also often measured $[1,6]$.

The flammability of the nanocomposites under investigation was also determined by the method of a cone calorimeter using an apparatus from Fire Testing Technology LTD. The tests were performed according to standard PNISO 5660 using $100 \times 100 \times 2 \mathrm{~mm}$ plates, which were conditioned in air at a temperature of $20 \pm 2{ }^{\circ} \mathrm{C}$ and $\mathrm{RH}$ $50 \pm 5 \%$, and then horizontally exposed to the action of heat radiation with an intensity of $50 \mathrm{~kW} / \mathrm{m}^{2}$.

\section{Results and discussion}

From the derivatographic analysis of NanoBents (ZS, ZW, ZR) and Nanofils (N2, N5, N15), it follows that they are characterised by a high thermal stability determined with coefficient $T_{5}$ as well as a considerable residue resulted from thermal decomposition, $P_{800}$ (Table 2). The montmorillonites tested undergo partial, four-stage decomposition taking place within the temperature range of 50-650 ${ }^{\circ} \mathrm{C}$ (Fig. 1) [7].

The first stage of thermal decomposition of modified nanoclays, taking place at $\Delta T_{1}=50-180{ }^{\circ} \mathrm{C}$, accompanied by a broadened exothermic process recorded in DTA curve, is due to the desorption of water and low-molecular substances present on the surface of nanoadditives. The thermal tests of montmorillonites have shown that all of them, with the exception of Nanofil N2, contain physically combined water in a quantity up to $3.3 \%$ by wt. (Table 2 ).

Although the modifiers of montmorillonite (MMT) in the form of ammonium compounds have been used in preparation of polymer/MMT nanocomposites, their
Table 2 The results of thermal analysis of montmorilonites

\begin{tabular}{llllll}
\hline Symbol & $Z_{\mathrm{H}_{2} \mathrm{O}} / \%$ & $T_{5} /{ }^{\circ} \mathrm{C}$ & $T_{R} /{ }^{\circ} \mathrm{C}$ & $\mathrm{d} m / \mathrm{d} t / \mathrm{mm}$ & $P_{800} / \%$ \\
\hline ZS & 3.3 & 190 & 190 & 7 & 60 \\
ZR & 2.8 & 235 & 215 & 1.5 & 72.2 \\
ZW & 2.2 & 235 & 210 & 3 & 72.2 \\
N2 & 0.0 & 205 & 170 & 5.0 & 78.0 \\
N5 & 2.2 & 230 & 210 & 3.0 & 63.3 \\
N15 & 1.7 & 210 & 195 & 5.0 & 56.1 \\
\hline
\end{tabular}

$Z_{\mathrm{H}_{2} \mathrm{O}}$ physically bounded water

$T_{5}$ temperature of montmorilonite, $5 \%$ mass loss

$T_{R}$ initial temperature of nanoadditive thermal decomposition $\mathrm{d} m / \mathrm{d} t$ maximum rate of nanofiller thermal decomposition $P_{800}$ residue after heating up to $T=800{ }^{\circ} \mathrm{C}$

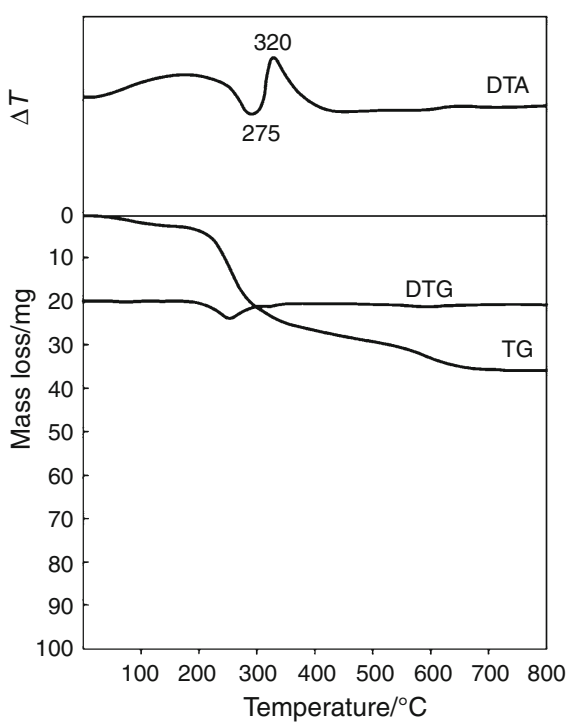

Fig. 1 Thermal curves of NanoBent ZS-1

common shortcoming is the poor thermal stability, which is connected with their thermal degradation. The thermal degradation of ammonium salts generally proceeds either by Hofmann's elimination or an $\mathrm{S}_{\mathrm{N}} 2$ nucleophilic substitution reaction.

The thermal decomposition of montmorillonite modifiers takes place at $\Delta T_{2}=180-300{ }^{\circ} \mathrm{C}$. The maximal rate of the thermal decomposition of the OLS takes place at about $240{ }^{\circ} \mathrm{C}$ (Fig. 1) and proceeds according to the Hofmann's degradation mechanism [4, 8]. The initial step includes the formation and desorption of olefin and amine, leaving acidic proton on the surface of the MMT at the site of the ammonium cation (Reactions 1,2). The existence of acidic proton, $\mathrm{H}^{+}$, may influence the chemical reactions of polymer at elevated temperature (Tables 3 and 4). 


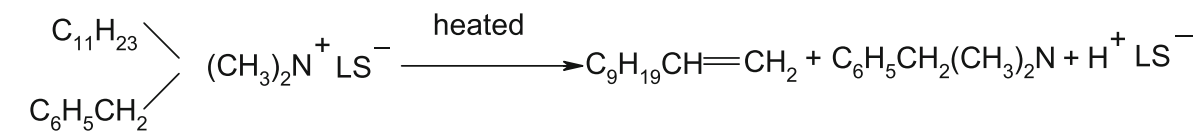

SBMAC
Reaction 2
$\left(\mathrm{C}_{11} \mathrm{H}_{23}\right)_{2}\left(\mathrm{CH}_{3}\right)_{2} \mathrm{~N}^{+} \mathrm{LS}^{-}-$heated $\longrightarrow \mathrm{C}_{9} \mathrm{H}_{19} \mathrm{CH}=\mathrm{CH}_{2}+\left(\mathrm{C}_{11} \mathrm{H}_{23}\right)_{2}\left(\mathrm{CH}_{3}\right)_{2} \mathrm{~N}+\mathrm{H}^{+} \mathrm{LS}^{-}$

SMAC

Reactions 1, 2. (LS represents the MMT layers in OLS).

From the analysis of the results obtained as well as from a literature review it follows that in the temperature range of $180-300{ }^{\circ} \mathrm{C}$, low-molecular-weight organic compounds are released first, which is accompanied by a considerable weight loss amounting from $11 \%$ in the case of montmorillonites $\mathrm{ZR}$ and $\mathrm{ZW}$ up to $23 \%$ in the case of montmorillonites ZS and N15, whilst the high-molecularweight organic species are still trapped by OLS matrix. With the increase in temperature to $300-500{ }^{\circ} \mathrm{C}, \Delta T_{3}$, the high-molecular organic compounds are not only decomposed but also released from OLS [7, 9, 10].

The final stage of the thermal decomposition of OLS, taking place at $\Delta T_{4}=500-650{ }^{\circ} \mathrm{C}$, is connected with

Table 3 The results of thermal analysis of peroxide vulcanizates of nitrile rubber

\begin{tabular}{|c|c|c|c|c|c|c|c|c|}
\hline Sample & MMT phr. & $T_{5} /{ }^{\circ} \mathrm{C}$ & $T_{50}{ }^{\circ} \mathrm{C}$ & $\mathrm{d} m / \mathrm{d} t / \mathrm{mm}$ & $T_{R \max } /{ }^{\circ} \mathrm{C}$ & $P_{w} / \%$ & $T_{s} /{ }^{\circ} \mathrm{C}$ & $P_{800} / \%$ \\
\hline $\mathrm{N}$ & 0 & 350 & 420 & 70 & 410 & 23 & 545 & 7 \\
\hline \multirow[t]{3}{*}{ NXZS } & 3 & 370 & 420 & 48 & 390 & 29 & 545 & 11 \\
\hline & 5 & 365 & 420 & 49 & 390 & 25 & 555 & 11 \\
\hline & 8 & 360 & 415 & 45 & 395 & 28 & 555 & 12 \\
\hline \multirow[t]{3}{*}{ NXZW } & 3 & 365 & 415 & 39 & 395 & 39 & 540 & 9 \\
\hline & 5 & 330 & 415 & 41 & 395 & 41 & 545 & 11 \\
\hline & 8 & 375 & 420 & 46 & 390 & 46 & 545 & 13 \\
\hline \multirow[t]{3}{*}{ NXZR } & 3 & 375 & 415 & 49 & 390 & 27 & 550 & 10 \\
\hline & 5 & 370 & 415 & 50 & 390 & 25 & 545 & 11 \\
\hline & 8 & 380 & 420 & 48 & 390 & 28 & 560 & 13 \\
\hline \multirow[t]{3}{*}{ NXN2 } & 3 & 340 & 410 & 65 & 400 & 23 & 545 & 7 \\
\hline & 5 & 325 & 410 & 49 & 405 & 25 & 540 & 8 \\
\hline & 8 & 325 & 410 & 77 & 410 & 25 & 520 & 9 \\
\hline \multirow[t]{3}{*}{ NXN5 } & 3 & 340 & 410 & 78 & 410 & 22 & 550 & 7 \\
\hline & 5 & 350 & 410 & 69 & 410 & 24 & 550 & 9 \\
\hline & 8 & 345 & 410 & 56 & 405 & 24 & 550 & 10 \\
\hline \multirow[t]{3}{*}{ NXN15 } & 3 & 335 & 415 & 64 & 405 & 21 & 580 & 7 \\
\hline & 5 & 340 & 415 & 83 & 404 & 23 & 535 & 7 \\
\hline & 8 & 315 & 410 & 63 & 400 & 23 & 530 & 7 \\
\hline
\end{tabular}

$N$ peroxide vulcanizate

NXZS vulcanizate $N$ containing $X$ parts by wt. of NanoBent ZS per 100 parts by wt. of NBR, where $X=3,5,8$

NXZW vulcanizate $N$ containing $X$ parts by wt. of NanoBent ZW per 100 parts by wt. of NBR, where $X=3,5,8$

NXZR vulcanizate $N$ containing $X$ parts by wt. of NanoBent ZR per 100 parts by wt. of NBR, where $X=3,5,8$

NXN2 vulcanizate $N$ containing $X$ parts by wt. of Nanofil 2 per 100 parts by wt. of NBR, where $X=3,5,8$

NXN5 vulcanizate $N$ containing $X$ parts by wt. of Nanofil 5 per 100 parts by wt. of NBR, where $X=3,5,8$

NXN15 vulcanizate $N$ containing $X$ parts by wt. of Nanofil 15 per 100 parts by wt. of NB, where $X=3,5,8$

$T_{5}$ and $T_{50}$ temperature of sample 5 and $50 \%$ mass loss, respectively

$T_{R \max }$ temperature of maximum rate of thermal decomposition of vulcanizate

$P_{w}$ residue after the thermal decomposition of vulcanizate

$T_{s}$ temperature of residue burning after the thermal decomposition of vulcanizate 
Table 4 The results of thermal analysis of sulphur vulcanizates of nitrile rubber

\begin{tabular}{|c|c|c|c|c|c|c|c|c|}
\hline Sample & MMT phr. & $T_{5} /{ }^{\circ} \mathrm{C}$ & $T_{50} /{ }^{\circ} \mathrm{C}$ & $\mathrm{d} m / \mathrm{d} t / \mathrm{mm}$ & $T_{R \max } /{ }^{\circ} \mathrm{C}$ & $P_{w} / \%$ & $T_{s} /{ }^{\circ} \mathrm{C}$ & $P_{800} / \%$ \\
\hline S & 0 & 315 & 405 & 52 & 395 & 23 & 540 & 7 \\
\hline \multirow[t]{3}{*}{ SXZS } & 3 & 370 & 415 & 38 & 390 & 31 & 540 & 13 \\
\hline & 5 & 350 & 415 & 31 & 390 & 31 & 525 & 12 \\
\hline & 8 & 365 & 415 & 29 & 400 & 30 & 540 & 14 \\
\hline \multirow[t]{3}{*}{ SXZW } & 3 & 350 & 420 & 38 & 390 & 29 & 545 & 12 \\
\hline & 5 & 345 & 415 & 36 & 390 & 32 & 530 & 14 \\
\hline & 8 & 345 & 410 & 38 & 400 & 28 & 535 & 13 \\
\hline \multirow[t]{3}{*}{ SXZR } & 3 & 360 & 410 & 38 & 385 & 28 & 545 & 13 \\
\hline & 5 & 350 & 415 & 42 & 400 & 31 & 530 & 13 \\
\hline & 8 & 340 & 415 & 39 & 400 & 33 & 530 & 16 \\
\hline \multirow[t]{3}{*}{ SXN2 } & 3 & 320 & 415 & 44 & 395 & 27 & 545 & 8 \\
\hline & 5 & 270 & 405 & 33 & 390 & 26 & 550 & 8 \\
\hline & 8 & 300 & 410 & 41 & 395 & 28 & 540 & 10 \\
\hline \multirow[t]{3}{*}{ SXN5 } & 3 & 310 & 405 & 46 & 390 & 25 & 555 & 9 \\
\hline & 5 & 330 & 415 & 39 & 400 & 24 & 565 & 11 \\
\hline & 8 & 275 & 405 & 34 & 390 & 23 & 555 & 9 \\
\hline \multirow[t]{3}{*}{ SXN15 } & 3 & 290 & 405 & 30 & 395 & 21 & 535 & 7 \\
\hline & 5 & 320 & 400 & 38 & 395 & 23 & 525 & 8 \\
\hline & 8 & 310 & 405 & 26 & 400 & 23 & 520 & 9 \\
\hline
\end{tabular}

S sulphur vulcanizate

SXZS vulcanizate $S$ containing $X$ parts by wt. of NanoBent ZS per 100 parts by wt. of NBR, where $X=3,5,8$

SXZW vulcanizate $S$ containing $X$ parts by wt. of NanoBent ZW per 100 parts by wt. of NBR, where $X=3,5,8$

SXZR vulcanizate $S$ containing $X$ parts by wt. of NanoBent ZR per 100 parts by wt. of NBR, where $X=3,5,8$

SXN2 vulcanizate $S$ containing $X$ parts by wt. of Nanofil 2 per 100 parts by wt. of NBR, where $X=3,5,8$

SXN5 vulcanizate $S$ containing $X$ parts by wt. of Nanofil 5 per 100 parts by wt. of NBR, where $X=3,5,8$

SXN15 vulcanizate $S$ containing $X$ parts by wt. of Nanofil 15 per 100 parts by wt. of NBR, where $X=3,5,8$

Fig. 2 Thermal curves

(a) peroxide vulcanizate, $N$,

(b) peroxide vulcanizate

containing 8 phr. Nanofil 2,

N8N2, (c) sulphur vulcanizate

containing 8 phr. Nanofil 2,

S8N2
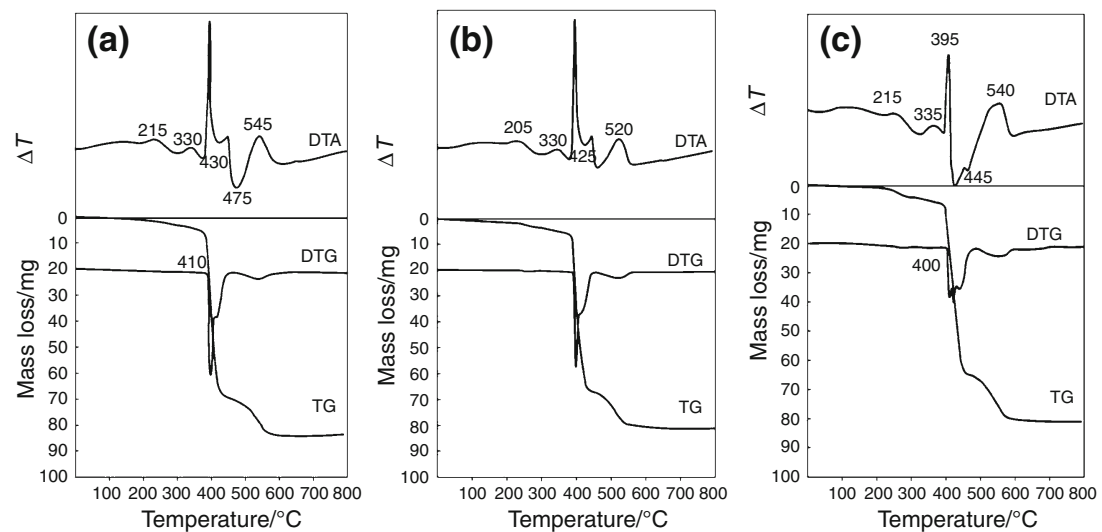

dehydration processes, i.e. with the release of water chemically combined with the montmorillonite surface.

The comparative analysis of DTA curves leads to a conclusion that the thermal transitions of nitrile rubber nanocomposites are of a similar character regardless of the network structure and the type and content of nanoadditive and the modification of MMT. The modifiers of MMT influence the thermal processes of cross-linked elastomer to a small extent (Fig. 2a,b,c; Tables 3 and 4).

The chemical transitions of the cross-linked nitrile rubber begin at $T \approx 170{ }^{\circ} \mathrm{C}$. The thermal cross-linking processes take place within two temperatures ranges. At $\Delta T_{1}=170 \div 270{ }^{\circ} \mathrm{C}$ they are due to the decomposition of hydroperoxide groups present in the polymer and formed in it 
by thermo-oxidative processes, whilst at $\Delta T_{2}=295 \div 370{ }^{\circ} \mathrm{C}$ due to the thermal polymerization of butadiene polymers. The thermal decomposition of vulcanizates proceeds at $\Delta T_{3}=370 \div 465{ }^{\circ} \mathrm{C}$, whilst at $\Delta T_{4}=465 \div 580{ }^{\circ} \mathrm{C}$ the residue of elastomer destruction is burned. The thermal stability of elastomers depends on the method of their cross linking and consequently on their spatial lattice structure [11].

The use of sulphur as cross linker results in the formation of sulphide crosswise bonds that are considerably weaker than the crosswise carbon-carbon bonds formed during cross linking with DCP. The thermal stability of the peroxide vulcanizate $(N)$ determined with coefficients $T_{5}$ and $T_{50}$ (Table 3 ) is therefore considerably higher than that of the sulphur vulcanizate $(S)$ (Table 4 ).

The results of derivatographic analysis given in Tables 3 and 4 show that the nanoadditives used do not unmistakably influence the thermal stability of the vulcanizates under investigation. NanoBents ZS, ZW and ZR used do not significantly change the thermal stability of peroxide vulcanizates determined with coefficients $T_{5}$ and $T_{50}$, whilst they clearly increase the values of these coefficients in the case of sulphur vulcanizates (Tables 3 and 4). The presence of Nanofils N2, N5 or N15 does not exert any positive influence on the thermal stability of the crosslinked butadiene-acrylonitrile elastomer, especially in the case of peroxide vulcanizates (Tables 3 and 4).

An important parameter that decides about the thermal stability of a polymeric material as well as its flammability is the rate of its thermal decomposition $(\mathrm{d} m / \mathrm{d} t)$. The decrease in the destruction rate of polymeric composites or nanocomposites exerts a positive influence on the reduction in their flammability. This is due to the formation of lower quantities of volatile, including flammable, products of pyrolysis passing to flame, which reduces the rate of freeradical reactions proceeding in this combustion zone. The nanoadditives used show different effects on the thermal decomposition rate depending on their network structure. NanoBents ZS, ZW and ZR do not exert any significant influence on the destruction rate of peroxide vulcanizates, whilst Nanofils N2, N5 and N15 clearly increase this rate (Table 3). The results of thermal analysis show that the nanoadditives used decrease the thermal decomposition rate of nitrile rubber cross linked with sulphur (Table 4).

The flammability of polymeric materials depends also on the quantity of thermal decomposition residue $\left(P_{w}\right)$ (Tables 3 and 4 ). The increase in this thermal parameter results in lower quantity of destruction products passing to flame. The presence of ZS, ZW or ZR clearly increases the value of $P_{w}$ in the case of elastomers cross linked with sulphur as well as with DCP (Tables 3 and 4). Thus, it can be concluded that the NanoBents used increase the capability of nitrile rubber to participate in the processes of thermal cyclization and carbonization. During the combustion of a thermally stable sample, this facilitates the formation of a boundary layer, which inhibits the flow of mass and energy between flame and sample. The insulating properties of the carbon layer are of course the better, the higher is the content of exfoliated structure in the investigated composite $[12,13]$. Taking into account the values of $P_{w}$ (Tables 3 and 4), one should assume that the exfoliation of Nanofils used in the elastomer matrix under investigation proceeds to a considerably lesser extent than that in the case of NanoBents.

The analysis of flammability test results leads to a conclusion that both NanoBents and Nanofils decrease the flammability of cross-linked NBR, as determined with the value of $\mathrm{OI}$ and the longest combustion time in air. From amongst the sample investigated the vulcanizates containing NanoBent ZS and Nanofil N2 are characterised by the highest value of OI and the longest combustion time in air (Tables 5 and 6).

The test results show no systematic effect of the nanoadditive quantity on the flammability of cross-linked nitrile rubber. The complex mechanism of processes taking place during both thermal decomposition and combustion of polymeric composites and nanocomposites makes it difficult to determine accurate effects of particular thermal stability parameters on their flammability. Nevertheless, in the case of the sulphur vulcanizates, one can observe clear effects of decreased thermal decomposition rate of elastomer in the presence of nanoaditives and increased

Table 5 Flammability test results of peroxide vulcanizates

\begin{tabular}{llll}
\hline Sample & MMT phr. & OI & $\begin{array}{l}\text { Time of } \\
\text { burning in air/s }\end{array}$ \\
\hline$N$ & 0 & 0.205 & 276 \\
NXZS & 3 & 0.342 & 285 \\
& 5 & 0.365 & 289 \\
NXZW & 8 & 0.375 & 394 \\
& 3 & 0.355 & 295 \\
& 5 & 0.371 & 358 \\
NXZR & 8 & 0.368 & 328 \\
& 3 & 0.353 & 317 \\
& 5 & 0.371 & 351 \\
NXN2 & 8 & 0.340 & 344 \\
& 3 & 0.291 & 340 \\
& 5 & 0.296 & 305 \\
NXN5 & 8 & 0.303 & 337 \\
& 3 & 0.293 & 323 \\
& 5 & 0.291 & 330 \\
NXN15 & 8 & 0.282 & 310 \\
& 3 & 0.283 & 303 \\
& 5 & 0.278 & 243 \\
& 8 & 0.269 & 237 \\
\hline
\end{tabular}


Table 6 Flammability test results of sulphur vulcanizates

\begin{tabular}{llll}
\hline Sample & MMT phr. & OI & $\begin{array}{l}\text { Time of } \\
\text { burning in air/s }\end{array}$ \\
\hline$S$ & 0 & 0.215 & 288 \\
SXZS & 3 & 0.315 & 344 \\
& 5 & 0.317 & 445 \\
SXZW & 8 & 0.333 & 407 \\
& 3 & 0.200 & 271 \\
& 5 & 0.174 & 273 \\
SXZR & 8 & 0.168 & 296 \\
& 3 & 0.283 & 284 \\
& 5 & 0.288 & 290 \\
SXN2 & 8 & 0.293 & 306 \\
& 3 & 0.298 & 311 \\
& 5 & 0.301 & 318 \\
SXN5 & 8 & 0.304 & 360 \\
& 3 & 0.286 & 321 \\
& 5 & 0.283 & 301 \\
SXN15 & 8 & 0.283 & 300 \\
& 3 & 0.288 & 312 \\
& 5 & 0.290 & 319 \\
& 8 & 0.265 & 282 \\
\hline
\end{tabular}

decomposition residue on the significant reduction in their flammability. The test results indicate that it is the barrier properties of nanoadditive used, which play an important role in reducing the flammability of the elastomer under investigation. Aluminosilicates are impermeable for vapours and gases, so during the thermal decomposition of nanocomposite, low-molecular products of its thermal decomposition can diffuse outside elastomer only through closely defined "ducts" by-passing the randomly situated aluminosilicate plates (so-called "labyrinth effect"). A considerable portion of diffusing destruction products is additionally trapped between montmorillonite layers, where it undergoes sequent processes, first of all, such as cross-linking and cyclization, which facilitates the formation of a carbon insulating layer. Also the diffusion of oxygen into the nanocomposite is considerably retarded, which limits the yield of radical reactions of degradation, destruction and polymer depolymerisation during combustion to increase its resistance to the action of flame [4].

The flammability tests of NBR composites comprise also fire hazard (Table 7).

From the comparative analysis of fire hazard parameters determined by means of a cone calorimeter, it follows that a significant influence on their values is exerted by the method of nitrile rubber cross-linking, i.e. the network structure (Table 7). The montmorillonites used do not exert any unmistakable influence on the fire hazard of the vulcanizates containing these nanoadditives. In the case of nitrile rubber cross linked with sulphur in the presence of nanoadditive, the time to sustained ignition (TTI) is significantly lengthened, which considerably reduces the fire hazard. Under the influence of nanofillers, the average heat release rate (HRR) and the smoke emission (specific extinction area) are increased, which is decidedly disadvantageous from the point of view of fire hazard. At the same time, however, under the influence of the montmorillonites used, the peak heat release rate $\left(\mathrm{HRR}_{\max }\right)$, total heat release (THR), the average effective heat of combustion (HOC) and the average mass loss rate (MLR) are decreased. The decreased values of these parameters show a positive effect of the nanoadditives on the limitation of

Table 7 Mean values of the parameters of NBR rubber vulcanizates determined by means of cone calorimeter

\begin{tabular}{|c|c|c|c|c|c|c|}
\hline Parameter & $N$ & N5ZS & N5N5 & $S$ & S5ZS & S5N5 \\
\hline TTI: Time to ignition/s & 38 & 36 & 40 & 32.7 & 40 & 38.5 \\
\hline HRR: Average heat release rate $/ \mathrm{kW} \mathrm{m}^{-2}$ & 174.5 & 357.5 & 354.21 & 218.06 & 309.1 & 341.2 \\
\hline HRRMAX: Peak heat release rate/kW m ${ }^{-2}$ & 2270.1 & 1187.9 & 1317.8 & 2378.5 & 1184.7 & 1289 \\
\hline THR: Total heat release/MJ $\mathrm{m}^{-2}$ & 70.1 & 67.2 & 70.1 & 69.8 & 64.9 & 69.2 \\
\hline HOC: Average effective heat of combustion/MJ m ${ }^{-2}$ & 35.3 & 28.9 & 29.3 & 36.4 & 28.6 & 28.7 \\
\hline MLR: Average mass loss rate/gs $\mathrm{m}^{-2}$ & 18.1 & 12.5 & 12.15 & 22.06 & 10.79 & 11.93 \\
\hline Average $\mathrm{CO}$ yield $/ \mathrm{kg} \mathrm{kg}^{-1}$ & 0.0674 & 0.0742 & 0.0767 & 0.0755 & 0.0733 & 0.0736 \\
\hline Average $\mathrm{CO}_{2}$ yield $/ \mathrm{kg} \mathrm{kg}^{-1}$ & 2.42 & 2.27 & 2.32 & 2.42 & 2.30 & 2.28 \\
\hline SEA Average specific extinction area $/ \mathrm{m}^{2} \mathrm{~kg}^{-1}$ & 869.2 & 1017.1 & 1074 & 992.35 & 1014.8 & 1077.3 \\
\hline $1 / t_{\text {flashover }} / \mathrm{kW} \mathrm{m}^{-2} \mathrm{~s}^{-1}$ & 59.73 & 32.99 & 32.94 & 72.73 & 29.25 & 33.48 \\
\hline $\mathrm{RTFH}_{\mathrm{CO} / \mathrm{CO}_{2}}$ & 0.0143 & 0.0106 & 0.0097 & 0.0220 & 0.0083 & 0.0096 \\
\hline
\end{tabular}

N5ZS vulcanizate $N$ containing 5 parts by wt. of NanoBent ZS per 100 parts by wt. of NBR

N5N5 vulcanizate $N$ containing 5 parts by wt. of Nanofil 5 per 100 parts by wt. of NBR

S5ZS vulcanizate $S$ containing 5 parts by wt. of NanoBent ZS per 100 parts by wt. of NBR

S5N5 vulcanizate $S$ containing 5 parts by wt. of Nanofil 5 per 100 parts by wt. of NBR 
fire hazard. This also results from the analysis of $1 / t_{\text {flashover }}$ parameters and toxicometric indicators $\mathrm{RTFH}_{\mathrm{CO} / \mathrm{CO}_{2}}$ (Table 7).

\section{Conclusions}

The thermal stability of the nanocomposites investigated depends on both the elastomer network structure and the type of montmorillonite.

The nanoadditives used reduce the flammability of cross-linked nitrile rubber and considerably limit its fire hazard. The barrier properties of the nanofillers under investigation play an important role in the limitation of butadiene-nitrile rubber flammability.

Acknowledgements This study was partly financed as research projects: NN508 398637, NN508 438136 and UDA-POIG 01.03.0100-044/08-00.

Open Access This article is distributed under the terms of the Creative Commons Attribution Noncommercial License which permits any noncommercial use, distribution, and reproduction in any medium, provided the original author(s) and source are credited.

\section{References}

1. Janowska G, Rybiński P, Helwig M, Dąbrowski W, Majewski K. Flammability of butadiene-acrylonitrile rubber. J Therm Anal Calorim. 2004;75:249-56.
2. Rybiński P, Janowska G, Antkowicz W, Krauze S. Thermal stability and flammability of butadiene-acrylonitrile rubber crosslinked with iodoform. J Therm Anal Calorim. 2005;81:9-13.

3. Janowska G, Przygocki W, Włochowicz A. Palność polimerów i materiałów polimerowych WNT, Warszawa 2007, ISSBN: 978-83-204-3299-2, 340 stron.

4. Leszczyńska A, Njuguna J, Pielichowski K, Banerjee JR. Polymer/montmorillonite nanocomposites with improved thermal properties. Part I. Thermochim Acta. 2007;453:75-96.

5. Ślusarski L, Janowska G, Szkodziński A, Niedomagała M, Harwaziński A. Układ do pomiaru wskaźnika tlenowego tworzyw sztucznych, naturalnych lub gumy, Patent PRL 129411, 1987.

6. Janowska G, Rybiński P, Kucharska-Jastrząbek A, Wójcik I, Wesołek D. Flammability of diene rubbers. J Therm Anal Calorim. 2010. doi:10.1007/s10973-010-0902-x.

7. Xie W, Gao Z, Liu K, Pan P-W, Vaia R, Hunter D, Singh A. Thermal characterization of organically modified montmorillonite. Thermochim Acta. 2001;367:339-50.

8. Gong F, Feng M, Zhao C, Zhang S, Yang M. Thermal properties of poly(vinyl chloride)/montmorillonite nanocomposites. Polym Degrad Stab. 2004;84:289-94.

9. Zidelkeir B, Abdelgoad M. Effect. of surfactant agent upon the structure of montmorillonite. J Therm Anal Calorim. 2008;94: $181-7$.

10. Lalikova S, Pajtasova M, Ondrusova D, Bazylakova T, Olsovsky M, Jona E, Mojumdar SC. Thermal and spectral properties of natural bentonites and their applications as reinforced nanofillers in polymeric materials. J Therm Anal Calorim. 2010;100:745-9.

11. Rybiński P, Janowska G. Influence of network structures of nitrile rubbers on their thermal properties. Polimery. 2009;54:275-82.

12. Gilman W. Flammability and thermal stability studies of polymer layered-silicate (clay) nanocomposites. Appl Clay Sci. 1999;15: 31-49.

13. Kotsilkova R, Petkova V, Pelovski Y. Thermal analysis of polymer-silicate nanocomposities. J Therm Anal Calorim. 2001; 64:591-8. 